\title{
Comparative Immunohistochemical Analysis of VASA, PLZF and THY1 in Goats and Sheep Suggests that these Markers are also Conserved in these Species
}

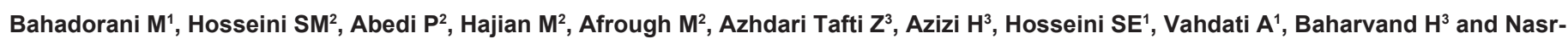
Esfahani $\mathrm{MH}^{2,4 *}$

${ }^{1}$ Department of Biology, Science and Research Branch, Islamic Azad University, Fars, Iran

2Department of Reproduction and Development, Reproductive Biomedicine Center, Royan Institute for Animal Biotechnology, ACECR, Isfahan, Iran

${ }^{3}$ Department of Stem Cells and Developmental Biology, Cell Sciences Research Center, Royan Institute for Stem Cell Biology and Technology, ACECR, Tehran, Iran

${ }^{4}$ Department of Embryology, Reproductive Biomedicine Center, Royan Institute for Reproductive Biomedicine, ACECR, Tehran, Iran

\begin{abstract}
Spermatogenesis is supported by a certain type of stem cell known as spermatogonial stem cell (SSC), which transforms information to the next generation. There is currently a wide acceptance of the great potential applications of SSCs for infertility treatment and production of transgenic farm animals. However, rodents are the only thoroughly studied mammals with respect to SSCs due to presence of specific antibodies for SSC markers such as PLZF and THY1 or germ cell marker such as VASA. However, limited information is available about the specific markers of SSCs in farm animals. Moreover, while it is generally believed that stem cell markers are mainly conserved among mammalian species, it is not clear if SSC markers have also remained conserved during species evolution. Through comparative immunohistochemical analysis of testis tissue of sheep, and goats with mice, rats and cattle, for which the original antibodies were rose, this study suggests that, despite the long evolutionary distance which exists between rodents and farm animals, germ cells and SSC markers may have remained conserved between these species. In addition, the results of this study suggest that these antibodies can be used to isolate, propagate and further explore SSCs in goat or sheep and possibly other species.
\end{abstract}

Keywords: Spermatogonial stem cell; Immunohistochemistry; Rodent; Farm animals

\section{Introduction}

Like other organs in the body, testes have tissue-specific stem cells known as spermatogonial (SSCs) or germ line stem cells (GSCs) [1]. Developmentally, SSCs originate from gonocytes in the prenatal testis, which in turn originate from primordial germ cells (PGCs) existing in the fetal genital ridge. Postnatally, gonocytes convert to undifferentiated A-spermatogonia at a species-specific time window (i.e. around day 6 in mice and day 180 in cattle) [2]. The undifferentiated A-spermatogonia include As (single), Apr (paired), and Aal (aligned) [3]. Then, through a highly orchestrated series of cell divisions, different classes of cells develop from Aal, that broadly divide into differentiating spermatogonia (A1, A2, A3, A4, intermediate, and B) and sperm (spermatocyte, spermatid, and spermatozoid) [4]. Daily, millions of spermatozoids are produced in an adult testis through the balance which exists between SSC self-renewal and differentiation $[5,6]$.

Great potential applications have been envisaged for SSCs in medicine and agriculture [7]. Under controlled in-vitro conditions, SSCs can attain embryonic stem cell (ESC)-like properties without the need for specific manipulations for pluripotency acquisition. This great flexibility of SSCs subverts the problems associated with induced pluripotent stem cells (iPS) and embryonic stem cells (ESCs) $[7,8]$. Moreover, it has been suggested that the state of naive pluripotency of mouse ES cells may be achieved in-vitro by the induction of PGCs [9]. However, considering the minute innate number of SSCs in the testis, development of efficient methods for characterization, isolation, enrichment and culture/expansion is imperative [10,11].

The mouse is the most thoroughly studied animal with respect to SSCs, and undoubtedly, this great progress is due to the establishment of several SSC-specific markers that facilitate the isolation, purification, manipulation and transplantation of SSCs in mice. However, progress with other animals has been modest, mainly due to limited information about specific SSC markers [12]. One approach to this limitation is to investigate the potential application of criteria, tools, and approaches that have been established for rodents over the past two decades. Such studies also provide an important platform for investigating the evolutionary conservation of SSC phenotypes and functions across different species.

To achieve this end, comparative immunohistochemical analysis has been suggested. Indeed, Hermann et al. (2007) observed a similar pattern of immunoreactivity with the stem/progenitor marker PLZF (Promyelocytic leukaemia zinc finger) in humans, monkeys and rodents [6]. Considering the limited information available about SSC markers in farm animals, particularly sheep and goats, this study was carried out to investigate whether specific germ cell markers such as VASA, PLZF and THY1 are conserved in these species. Therefore,

*Corresponding author: Mohammad H Nasr-Esfahani, Department of Reproduction and Development, Royan Institute for Animal Biotechnology, ACECR, Esfahan, Iran, Tel: (+) 98311 2612900-3; Fax: (+) 983112605525 ; E-mail: mh.nasr-esfahani@royaninstitute.org

Received August 25, 2011; Accepted October 10, 2011; Published October 14 2011

Citation: Bahadorani M, Hosseini SM, Abedi P, Hajian M, Afrough M, et al. (2011) Comparative Immunohistochemical Analysis of VASA, PLZF and THY1 in Goats and Sheep Suggests that these Markers are also Conserved in these Species. J Cytol Histol 2:126. doi:10.4172/2157-7099.1000126

Copyright: (c) 2011 Bahadorani M, et al. This is an open-access article distributed under the terms of the Creative Commons Attribution License, which permits unrestricted use, distribution, and reproduction in any medium, provided the original author and source are credited. 
Citation: Bahadorani M, Hosseini SM, Abedi P, Hajian M, Afrough M, et al. (2011) Comparative Immunohistochemical Analysis of VASA, PLZF and THY1 in Goats and Sheep Suggests that these Markers are also Conserved in these Species. J Cytol Histol 2:126. doi:10.4172/21577099.1000126

antibodies against these markers were used with their corresponding control.

\section{Materials and Methods}

\section{Chemicals and antibodies}

Unless otherwise specified, all chemicals were obtained from Sigma Chemical Co. (St. Louis, Mo, USA). The primary antibodies used were rabbit anti-VASA (VAS-ATP-dependent RNA helicase) DDX4 (DEAD-box protein 4, Abcam, UK), rabbit anti-THY1 (thymocyte antigen, Abcam, UK), and goat anti-PLZF (Santa Cruz Biotechnology, USA). Goat anti-rabbit IgG-FITC (Fluorescein isothiocyanate conjugated) and mouse anti-goat IgG FITC (Chemicon, Germany) were used as secondary antibodies.

\section{Preparation of testis sections}

Testes of a healthy young mature bull (Bos taurus, Holstein, 9-12 months), ram (Ovis aries, Bakhtiari, 9-15 months), and buck (Capra hircus, Naieni, 12-15 months) were collected immediately after slaughter and transported to lab on ice within one hour. Young mature rats (Rattus norvegicus, two months) and mice (Mus musculus, strain NMRI, two months) were killed by cervical dislocation and their testes were removed. After removal of scrotum and tunica albuginae, testes were washed with ice-cold phosphate buffer saline (PBS, Gibco, UK). The testes were then cut to small pieces, fixed with $4 \%$ paraformaldehyde and embedded in paraffin[13,14]. For the histological analysis, the samples were sectioned into 5 - $\mu \mathrm{m}$ thickness and stained with immunofluorescence antibodies.

\section{Immunostaining}

Immunostaining was performed according to Borjigin et al. [15] with minor modifications. Briefly, five slides were washed thrice with PBS containing $0.05 \%$ tween-20 (PBST) for 15 minutes. Since aldehyde fixatives such as PF induce protein cross-link formation which masks the antigen sites in tissue specimens, giving weak or false negative immunostaining, antigen retrieval was carried out to remove masking and cross-linked proteins [16-18]. For this purpose, the trypsin based solution was prepared freshly by mixing the same volumes of $0.5 \%$ trypsin (Gibco, UK) and $1 \%$ calcium chloride in distilled water. The slides were exposed to antigen retrieval solution for 15-20 minutes. To preclude non-specific binding sites, slides were also treated with blocking solution containing 5\% BSA in PBST for one hour at $37^{\circ} \mathrm{C}$. An additional incubation with $0.5 \%$ triton-X100 was performed before blocking for detection of VASA and PLZF markers. Slides were then immunostained with primary antibodies [(rabbit anti-VASA antibody (1:400), rabbit anti-THY1 (1:100), and goat anti-PLZF (1:100)] overnight at $4^{\circ} \mathrm{C}$. Primary antibodies were diluted with PBST containing 2.5\% BSA. Slides were then washed thrice with PBST, ten minutes each and treated with an appropriate secondary antibody (goat anti-rabbit IgG-FITC (1:80) for anti-THY1 and antiVASA primary antibodies, or mouse anti-goat IgG-FITC (1:50) for anti-PLZF). All secondary antibodies were diluted with PBST and used for one hour at $37^{\circ} \mathrm{C}$. Immunostained sections were rinsed three times with PBST followed by nuclear staining with 4',6- diamidino-2phenylindol (DAPI, $5 \mu \mathrm{g} / \mathrm{ml}$, two minutes). Slides were then washed and cover slipped with a drop of Enthelan glue. Slides were observed under an epi-fluorescent microscope (Olympus IX71, Japan) equipped with a stabilized HBO100 mercury vapor lamp and $490 \mathrm{~nm}$ excitation and $525 \mathrm{~nm}$ emission filters. Digital images were taken with a high sensitivity camera (Olympus DP-72, Japan) operated on DP2-BSW software. Positive controls for each primary antibody were prepared according to its data sheet. Accordingly, rat, bull, and mouse testicular sections were used as positive controls for anti-THY1, anti-VASA, and anti-PLZF, respectively.

\section{Results and Discussion}

SSCs are known to be located on the basement membrane of seminiferous tubules. Therefore, in this study SSCs were recognized according to their basal location [19], in addition to their high nucleus/ cytoplasm ratio [20] and dense appearance of the nuclei H\&E staining [21].

VASA distinguishes all germ cells, except sperm, in goats and sheep

The family of VASA genes comprises highly conserved genes specifically expressed in the germ cell lineage. The expression of VASA was first detected in germ line stem cells (GSCs) in the ovary and during the early stages of spermatogenesis in the testis in Drosophila [22]. VASA expression, which has been detected in both vertebrates and invertebrates, is necessary for germ cell formation and development [23]. Importantly, knockout mice lacking mvh (mouse VASA homologue) were infertile due to testicular atrophy resulting from abnormal proliferation and colonization of the PGCs [24]. It has been established in humans that anti-VASA antibody staining is relatively weak to intermediate in spermatogonia, strong in spermatocytes/spermatids, and absent in spermatozoa [25]. Reactivity of VASA antibody has been demonstrated in mice and predicted in humans (100\% identity with immunogen), rats (92\% identity with immunogen), cattle (92\% identity with immunogen) and pigs (100\% identity with immunogen) due to sequence homology [26]. However, its reactivity with other species has not been determined. Accordingly, the results of this study indicate that in addition to cattle, mice and rats, VASA antibody can be used for recognition of germ cells in sheep and goats. This cytoplasmic protein was detected from spermatogonia (the
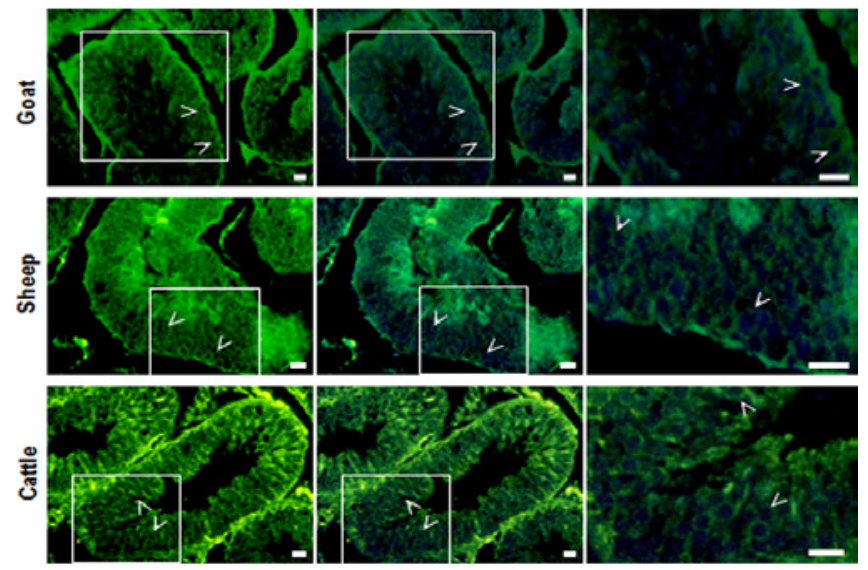

Figure 1: Comparative immunohistochemical analysis reveals cytoplasmic germ cell marker VASA, in goat, sheep and cattle. Left panel shows VASA staining, and middle panel shows merge of VASA and DAPI. Right panel shows higher magnification of the marked area in the middle panel. Cattle were considered as positive control according to the data sheet for the VASA antibody. Bar $=50 \mu \mathrm{m}$. 
Citation: Bahadorani M, Hosseini SM, Abedi P, Hajian M, Afrough M, et al. (2011) Comparative Immunohistochemical Analysis of VASA, PLZF and THY1 in Goats and Sheep Suggests that these Markers are also Conserved in these Species. J Cytol Histol 2:126. doi:10.4172/21577099.1000126

base of seminiferous tubule) through spermatid (at the lumen) stages in goats and sheep in parallel to cattle (Figure 1). In agreement with our results, the VASA protein, as a member of an ATP-dependent RNA helicase of the DEAD-box family protein [27], has been reported to have a conserved structure and therefore, the PCR technique has been used to verify this point across a wide range of species from Caenorhabditis elegans to humans [24]. Toyooka et al. [28] reported that VASA was exclusively expressed in germ cells following colonization of gonads and also in germ cells in meiotic stage in mice of both sexes. In addition, Raz [23] suggested that this marker is essential for the maintenance of toti-potentiality of PGC, even though it remains present during the differentiation of germ cells up to the spermatid stages.

PLZF is a conserved marker of undifferentiated germ cells in cattle, sheep, and goats

Promyelocytic leukaemia zinc finger (PLZF) is a DNA sequencespecific transcriptional repressor that represses the transcription of kit, a hallmark of spermatogonial differentiation and thereby maintains the source of SSCs in mice [29]. PLZF has a regulatory role on differentiation pathways, particularly involved in stem cell maintenance [30]. Accordingly, it was demonstrated that PLZF-null mice have defective sperm production which is caused by the inability of spermatogonial stem cells to self-renew. Considering the fact that germ cells may be epigenetically regulated through DNA methylation, it has been proposed that PLZF may regulate stem cell maintenance through modification of epigenetic marks and transcription [31,32]. Through several studies, it has been established that PLZF antibody specifically reacts with stem cells, and there are several reports about the cross-reactivity of the PLZF antibody with a wide range of animal species, from Caenorhabditis elegans to humans [32]. This study, for the first time, indicated that undifferentiated spermatogonia in goats and sheep expressed PLZF, which was evident from positive reaction with the anti-PLZF polyclonal antibody (Figure 3). Previously, it has been established that PLZF reacts with only SSCs in mice, cattle, and rats. Therefore, since positive PLZF-stained cells were only observed

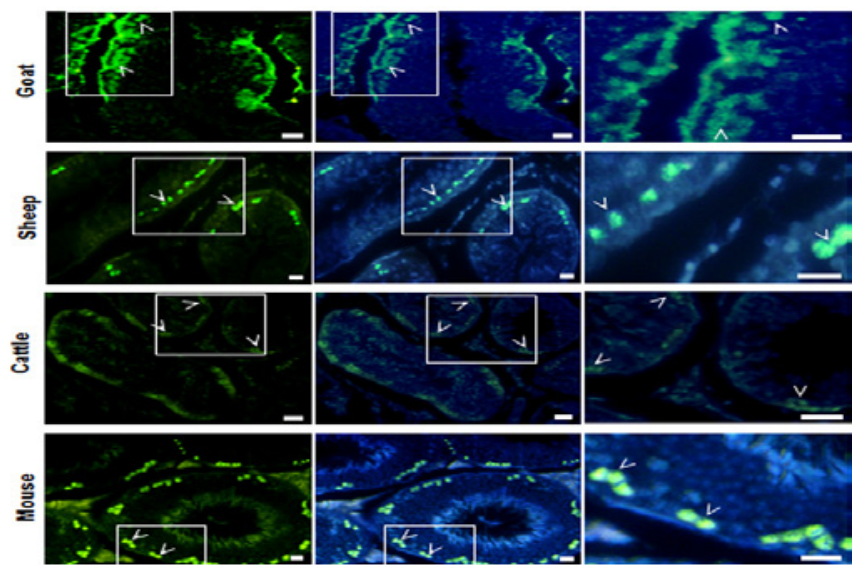

Figure 2: Comparative immunohistochemical analysis reveals nuclear germ cell marker PLZF, in goat, sheep, cattle and mouse. Left panel shows PLZF staining, and middle panel shows merge of PLZF and DAPI. Right panel shows magnification of the marked area in the middle panel. White arrows represent germ cells. Mice were taken as positive control according to the data sheet for the PLZF antibody. Bar $=50 \mu \mathrm{m}$.

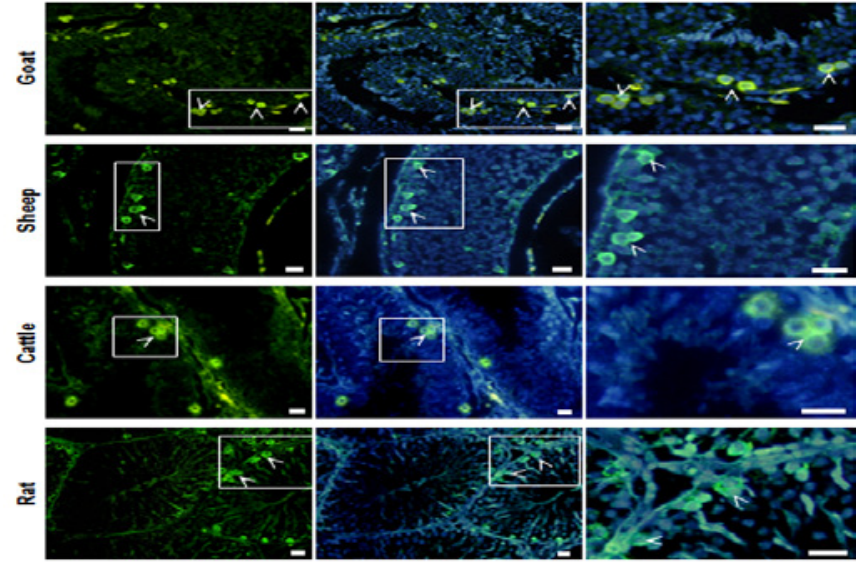

Figure 3: Comparative immunohistochemical analysis reveals cell surface germ cell marker THY1, in goat, sheep, cattle and rat. Left and middle pane shows THY1 staining and merge of THY1 and DAPI, respectively. Right panel shows the marked area in the middle panel with higher magnification. White arrows represent germ cells. Rats were taken as positive control according to the data sheet for the THY1 antibody. Bar $=50 \mu \mathrm{m}$.

at the base of seminiferous tubules (Figure 2), it seems that PLZF is specifically expressed in undifferentiated spermatogonia.

\section{THY1 (CD90) is a conserved SSC-specific marker in goats and sheep}

Unlike VASA and PLZF which are cytoplasmic and nuclear markers respectively, THY1 is a surface marker also known as CD90 (cluster of differentiation 90). THY1 is a $25-37 \mathrm{kDa}$ GPI (N-glycosylated, glycophosphatidylinositol) anchored protein originally discovered as a thymocyte antigen [33] and later observed to be present in some sources of stem cells including SSCs [34]. THY1 was initially introduced as a specific marker of murine spermatogonial stem cells [35] and recently, Reding et al. demonstrated that THY 1 can also be considered as a SSCspecific marker in cattle [36]. The results of this study indicate that the reactivity of anti-THY1 with the surface area of certain cells, on the basement membrane of seminiferous tubules, is a characteristic of SSCs (Figure 3). Therefore, it seems that THY1 may be considered as a SSC-specific marker in goats and sheep.

\section{Concluding Remarks}

Considering the scarce innate number of SSCs in the testis, establishment of the antigenic profile that is specially expressed in SSCs is crucial for their selective separation and enrichment. In this respect, the mouse is the most thoroughly studied mammalian species [35] and PLZF, VASA, and THY1 are the established germ cell markers in rodents. The results of this study suggest the potential application of VASA, PLZF and THY1 as suitable markers for the assessment and manipulation of SSCs in goats and sheep. Among animals, there is conservation of proliferation and differential pathways. In this study, it was suggested that the three germ cell markers VASA, PLZF and THY 1 can be used for goat and sheep germ cell studies, despite a long evolutionary distance between rodents and ungulates. These results show that sheep, goats, cattle and mice share some specific SSC antigen despite lineage differences. These results indicate that the antibodies used in this study can also be used for the assessment of in-vitro research on SSCs when fixed similarly. 
Citation: Bahadorani M, Hosseini SM, Abedi P, Hajian M, Afrough M, et al. (2011) Comparative Immunohistochemical Analysis of VASA, PLZF and THY1 in Goats and Sheep Suggests that these Markers are also Conserved in these Species. J Cytol Histol 2:126. doi:10.4172/21577099.1000126

\section{Acknowledgement}

This study was funded by a grant from the Royan Institute (P83P88213). Authors declare that there is no conflict of interest in this study.

\section{References}

1. Mizukami T, Kuramitsu M, Takizawa K, Momose $\mathrm{H}$, Masumi A, et al. (2008) Identification of transcripts commonly expressed in both hematopoietic and germ-line stem cells. Stem Cells Dev 17: 67-80.

2. Curtis SK, Amann RP (1981) Testicular development and establishment of spermatogenesis in Holstein bulls. J Anim Sci 53: 1645-1657.

3. de Rooij DG, Russell LD (2000) All you wanted to know about spermatogonia but were afraid to ask. J Androl 21: 776-798.

4. Oakberg EF (1971) Spermatogonial stem-cell renewal in the mouse. Anat Rec 169: $515-531$

5. Sharpe R (1994) Regulation of spermatogenesis: The Physiology of Reproduction. (2ndedn), Raven Press, New York.

6. Hermann BP, Sukhwani M, Lin CC, Sheng Y, Tomko J, et al. (2007) Characterization, cryopreservation, and ablation of spermatogonial stem cells in adult rhesus macaques. Stem Cells 25: 2330-2338.

7. Guan K, Nayernia K, Maier LS, Wagner S, Dressel R, et al. (2006) Pluripotency of spermatogonial stem cells from adult mouse testis. Nature 440: 1199-1203.

8. Guan K, Wolf F, Becker A, Engel W, Nayernia K, et al. (2009) Isolation and cultivation of stem cells from adult mouse testes. Nat Protoc 4: 143-154.

9. Nichols J, Smith A (2011) The origin and identity of embryonic stem cells, Development 138: 3-8.

10. Phillips BT, Gassei K, Orwig KE (2010) Spermatogonial stem cell regulation and spermatogenesis. Philos Trans R Soc Lond B Biol Sci 365: 1663-1678.

11. Kanatsu-Shinohara M, Ogonuki N, Miki H, Inoue K, Morimoto H, et al. (2010) Genetic influences in mouse spermatogonial stem cell self-renewal. J Reprod Dev 56: 145-153.

12. Kubota H, Avarbock MR, Brinster RL (2003) Spermatogonial stem cells share some, but not all, phenotypic and functional characteristics with other stem cells. Proc Natl Acad Sci U S A 100: 6487-6492.

13. Jelodar GA, Gholami S, Jafarpour F (2007) Effect of GnRH on guinea pig endometrium at preimplantation stage. Indian Journal of Exprimental Biology 45: $242-246$

14. Kiernan JA (2008) Histological and Histochemical Methods: Theory and Practice. (4th edn), Bloxham, UK: Scion.

15. Borjigin U, Davey R, Hutton K, Herrid M (2010) Expression of promyelocytic leukaemia zinc-finger in ovine testis and its application in evaluating the enrichment efficiency of differential plating. Reprod Fertil Dev 22: 733-742.

16. Ashton-Key M, Jessup E, Isaacson PG (1996) Immunoglobulin light chain staining in paraffin-embedded tissue using a heat mediated epitope retrieval method. Histopathology 29: 525-531.

17. Kashima K, Yokoyama S, Daa T, Nakayama I, Nickerson PA, et al. (1997) Cytoplasmic biotin-like activity interferes with immunohistochemical analysis of thyroid lesions: a comparison of antigen retrieval methods. Mod Pathol 10: 515519

18. Frost AR, Sparks D, Grizzle WE (2000) Methods of antigen recovery vary in their usefulness in unmasking specific antigens in immunohistochemistry. App Immunohistochem Mol Morphol 8: 236-243.

19. Yu F, Ding LJ, Sun GB, Sun PX, He XH, et al. (2010) Transgenic sperm produced by electrotransfection and allogeneic transplantation of chicken fetal spermatogonial stem cells. Mol Reprod Dev 77: 340-347

20. Izadyar F, Wong J, Maki C, Pacchiarotti J, Ramos T, et al. (2011) Identification and characterization of repopulating spermatogonial stem cells from the adult human testis. Hum Reprod 26: 1296-1306.

21. Aponte PM, Soda T, Teerds KJ, Mizrak SC, van de Kant HJ, et al. (2008)
Propagation of bovine spermatogonial stem cells in vitro. Reproduction 136 543-557.

22. Tanaka SS, Toyooka Y, Akasu R, Katoh-Fukui Y, Nakahara Y, et al. (2000) The mouse homolog of Drosophila Vasa is required for the development of male germ cells. Genes Dev 14:841-53.

23. Raz E (2000) The function and regulation of vasa-like genes in germ-cell development. Genome Biol 1: 1017.

24. Zeeman AM, Stoop H, Boter M, Gillis AJ, Castrillon DH, et al. (2002) VASA is a specific marker for both normal and malignant human germ cells. Lab Invest 82: 159-166.

25. Castrillon DH, Quade BJ, Wang TY, Quigley C, Crum CP (2000) The human VASA gene is specifically expressed in the germ cell lineage. Proc Natl Acad Sci U S A 97: 9585-9590.

26. http://www.abcam.com/DDX4-MVH-antibody-Primordial-Germ-Cell-Markerab13840.html

27. Montiel E, Guillomot M, Rojas M, Bustos-Obregon E, Flechon J (2001) Primordial germ cell characterization by immunohistochemistry of vasahomologue protein in preimplantational rabbit embryos. Int J Dev Biol 45 : 9914-9914.

28. Toyooka Y, Tsunekawa N, Takahashi Y, Matsui Y, Satoh M, et al (2000) Expression and intracellular localization of mouse Vasa-homologue protein during germ cell development. Mech Dev 93: 139-149.

29. Filipponi D, Hobbs RM, Ottolenghi S, Rossi P, Jannini EA, et al. (2007) Repression of kit expression by Plzf in germ cells. Mol Cell Biol 27: 6770-6781.

30. Kotaja N, Sassone-Corsi P (2004) Plzf pushes stem cells. Nat Genet 36: 551 553.

31. Buaas FW, Kirsh AL, Sharma M, McLean DJ, Morris JL, et al. (2004) Plzf is required in adult male germ cells for stem cell self-renewal. Nat Genet 36: 647652.

32. Costoya JA, Hobbs RM, Barna M, Cattoretti G, Manova K, et al. (2004) Essential role of Plzf in maintenance of spermatogonial stem cells. Nat Genet 36: 653-659.

33. Zhang T, Xiong H, Kan LX, Zhang CK, Jiao XF, et al. (1999) Genomic sequence, structural organization, molecular evolution, and aberrant rearrangement of promyelocytic leukemia zinc. Proc Natl Acad Sci USA 96: 11422-11427.

34. Rege TA, Hagood JS (2006) Thy-1 as a regulator of cell-cell and cell-matrix interactions in axon regeneration, apoptosis, adhesion, migration, cancer, and fibrosis. FASEB J 20: 1045-1054.

35. He Z, Kokkinaki M, Jiang J, Dobrinski I, Dym M (2010) Isolation, characterization, and culture of human spermatogonia. Biol Reprod 82: 363-372.

36. Reding SC, Stepnoski AL, Cloninger EW, Oatley JM (2010) THY1 is conserved marker of undifferentiated spermatogonia in the pre-pubertal bul testis. Reproduction 139: 893-903. 